Editorial

\title{
Introduction to the Special Issue: "State-of-the-Art Virtual/Augmented Reality and 3D Modeling Techniques for Virtual Urban Geographic Experiments"
}

\author{
Jianming Liang $1,2,3, *(\mathbb{D})$, Jianhua Gong ${ }^{2,4, *}$ and Yu Liu ${ }^{5, *}$ (i) \\ 1 Key Laboratory of Urban Land Resources Monitoring and Simulation, Ministry of Land \\ and Resources of China, Shenzhen 518034, China \\ 2 State Key Laboratory of Remote Sensing Science, Institute of Remote Sensing and Digital Earth, \\ Chinese Academy of Sciences, Beijing 100101, China \\ 3 School of Life Sciences, Arizona State University, Tempe, AZ 85287, USA \\ 4 Zhejiang-CAS Application Center for Geoinformatics, Jiashan 314100, China \\ 5 Institute of Remote Sensing and Geographical Information Systems, Peking University, Beijing 100871, China \\ * Correspondence: ljm355@163.com (J.L.); gongjh@radi.ac.cn (J.G.); liuyu@urban.pku.edu.cn (Y.L.); \\ Tel./Fax: +86-10-6484-9299 (J.G.)
}

Received: 31 August 2018; Accepted: 4 September 2018; Published: 5 September 2018

Keywords: urban; VGE; 3D modeling; VR/AR

Virtual geographic environments (VGEs) are computerized representations of geographic environments [1,2]. VGE-assisted experiments aimed at solving geographic problems and understanding geographic scenarios are known as computer-aided geographic experiments (CAGEs) [1,2]. A city is a dynamic environment subject to the interplay between physical and social processes that give rise to complex geographic problems. A special type of CAGEs is therefore needed to address these complex urban geographic problems, which we define as virtual urban geographic experiments (VUGEs).

Recent advances in virtual reality (VR), augmented reality (AR), artificial intelligence (AI), and remote sensing (RS) open up new opportunities for the development of VUGEs. This Special Issue focuses on innovative applications of these state-of-the-art technologies for VUGEs. A total of 18 papers was published in this Special Issue and they can be categorized into the following four groups:

(1) VR/AR technologies. Mobile-based VR systems were developed and shown to have the potential to support decision-making in cases such as flood risk management [3] and wind park planning [4]. Moreover, multiple studies on the development and application of AR technologies were presented. Ma et al. developed a new method to enhance three-dimensional (3D) registration in indoor AR systems [5]. Li et al. overcame the technical challenge of real-time rendering so that AR can be efficiently used in urban underground pipeline management [6]. Additionally, You et al. emphasized the application of AR in urban warfare as it can potentially improve situational awareness and ultimately lead to enhanced decision-making efficiency and reduced injuries [7].

(2) 3D modeling and information extraction. VUGEs relies on 3D modeling for constructing virtual environments; Construction of coupled indoor/outdoor VGEs is particularly challenging. Zhang et al. proposed to integrate unmanned aerial vehicle (UAV)-based outdoor 3D reconstruction, computer-aided design (CAD)-based indoor modeling and iBeacon-based indoor positioning in this regard and presented a prototype indoor-outdoor VGE to support urban emergency response [8]. Additionally, new methods for the extraction of urban features from LiDAR point clouds were explored in two studies $[9,10]$. Traffic is an integral aspect of both the real and virtual world. In urban VGEs, the representation of complex road networks is especially important, as it can systematically link 
together people, locations, and materials [11]. With the state-of-the-art AI, 3D information extraction techniques can even be extended to accommodate dynamic features such as traffic police gestures [12]. Unlike RS-based static 3D reconstruction, surveillance cameras capture dynamic information including moving objects and their trajectories, which can be effectively extracted and integrated into VUGEs [13]. With the massive 3D information available, the generalization of level-of-details (LODs) may sometimes be needed to enhance visualization performance [14]. Finally, Saeedi et al. presented an "Overview of the OGC CDB Standard for 3D Synthetic Environment Modeling and Simulation" in response to the challenges of processing, managing, and analyzing Big Data in 3D synthetic environment modeling and simulation [15].

(3) Modeling of geo-processes. Tang et al. developed a physically-based method to simulate light distribution in plant canopies which has the potential to be used in urban forestry policy-making [16]; Yin et al. developed a debris flow visual simulation framework and showed how it can facilitate debris flow risk management in residential areas [17].

(4) Modeling of human behavior and cognition. Traditionally, VGE research has largely concentrated on physical dimensions. Recently, there has been an increasing emphasis on human dimensions. By incorporating human behavioral and cognitive characteristics, VGEs can better serve research in terms of human-environmental interactions. An effective approach to incorporating human behavior simulation in a VGE is through the social force model [18]. In many cases, however, the participation of real humans is needed to make the studies more realistic. Integrating human behavior simulation and immersive VR brings real humans into integration with virtual humans and the environment. Shen et al.'s heterogeneous distributed virtual geographic environment (HDVGE) effectively overcame the challenge of collaboration of heterogeneous immersive VR clients and accommodates both real human participation and crowd simulation in VGE [19], which could potentially be used in many urban scenarios including fire drills and evacuation. Zhang et al. proposed a novel virtual cognitive experiments framework by constructing a user 'evaluative' immersive environment, as opposed to the traditional 'interpretive' virtual environment [20]. The proposed virtual cognitive experiments framework implemented a responsive mechanism to keep track of users' cognitive processes during the experiments [20].

Author Contributions: J.L., J.G. and Y.L. organized this special issue.

Funding: This research was funded by the Open Fund of Key Laboratory of Urban Land Resources Monitoring and Simulation, Ministry of Land and Resources grant number \#KF-2016-02-004.

Conflicts of Interest: The authors declare no conflict of interest.

\section{References}

1. Lin, H.; Chen, M.; Lu, G.; Zhu, Q.; Gong, J.; You, X.; Wen, Y.; Xu, B.; Hu, M. Virtual geographic environments (VGEs): A new generation of geographic analysis tool. Earth-Sci. Rev. 2013, 126, 74-84. [CrossRef]

2. Lin, H.; Chen, M.; Lu, G. Virtual geographic environment: A workspace for computer-aided geographic experiments. Ann. Assoc. Am. Geogr. 2013, 103, 465-482. [CrossRef]

3. Hu, Y.; Zhu, J.; Li, W.; Zhang, Y.; Zhu, Q.; Qi, H.; Zhang, H.; Cao, Z.; Yang, W.; Zhang, P. Construction and Optimization of Three-Dimensional Disaster Scenes within Mobile Virtual Reality. ISPRS Int. J. Geo-Inf. 2018, 7, 215. [CrossRef]

4. YU, T.; Behm, H.; Bill, R.; Kang, J. Validity of VR Technology on the Smartphone for the Study of Wind Park Soundscapes. ISPRS Int. J. Geo-Inf. 2018, 7, 152. [CrossRef]

5. Ma, W.; Xiong, H.; Dai, X.; Zheng, X.; Zhou, Y. An Indoor Scene Recognition-Based 3D Registration Mechanism for Real-Time AR-GIS Visualization in Mobile Applications. ISPRS Int. J. Geo-Inf. 2018, 7, 112. [CrossRef]

6. Li, W.; Han, Y.; Liu, Y.; Zhu, C.; Ren, Y.; Wang, Y.; Chen, G. Real-Time Location-Based Rendering of Urban Underground Pipelines. ISPRS Int. J. Geo-Inf. 2018, 7, 32. [CrossRef]

7. You, X.; Zhang, W.; Ma, M.; Deng, C.; Yang, J. Survey on Urban Warfare Augmented Reality. ISPRS Int. J. Geo-Inf. 2018, 7, 46. [CrossRef] 
8. Zhang, X.; Chen, Y.; Yu, L.; Wang, W.; Wu, Q. Three-Dimensional Modeling and Indoor Positioning for Urban Emergency Response. ISPRS Int. J. Geo-Inf. 2017, 6, 214. [CrossRef]

9. Xing, X.-F.; Mostafavi, M.-A.; Chavoshi, S.H. A Knowledge Base for Automatic Feature Recognition from Point Clouds in an Urban Scene. ISPRS Int. J. Geo-Inf. 2018, 7, 28. [CrossRef]

10. Chen, Y.-C.; Lin, B.-Y.; Lin, C.-H. Consistent Roof Geometry Encoding for 3D Building Model Retrieval Using Airborne LiDAR Point Clouds. ISPRS Int. J. Geo-Inf. 2017, 6, 269. [CrossRef]

11. Zheng, P.; Tao, H.; Yue, S.; Wu, M.; Lv, G.; Zhou, C. A Representation Method for Complex Road Networks in Virtual Geographic Environments. ISPRS Int. J. Geo-Inf. 2017, 6, 372. [CrossRef]

12. Ma, C.; Zhang, Y.; Wang, A.; Wang, Y.; Chen, G. Traffic Command Gesture Recognition for Virtual Urban Scenes Based on a Spatiotemporal Convolution Neural Network. ISPRS Int. J. Geo-Inf. 2018, 7, 37. [CrossRef]

13. Xie, Y.; Wang, M.; Liu, X.; Wu, Y. Surveillance Video Synopsis in GIS. ISPRS Int. J. Geo-Inf. 2017, 6, 333. [CrossRef]

14. Liu, P.; Li, C.; Li, F. Texture-Cognition-Based 3D Building Model Generalization. ISPRS Int. J. Geo-Inf. 2017, 6, 260. [CrossRef]

15. Saeedi, S.; Liang, S.; Graham, D.; Lokuta, M.F.; Mostafavi, M.A. Overview of the OGC CDB Standard for 3D Synthetic Environment Modeling and Simulation. ISPRS Int. J. Geo-Inf. 2017, 6, 306. [CrossRef]

16. Tang, L.; Yin, D.; Chen, S.; Chen, C.; Huang, H.; Lin, D. Virtual Geographic Simulation of Light Distribution within Three-Dimensional Plant Canopy Models. ISPRS Int. J. Geo-Inf. 2017, 6, 405. [CrossRef]

17. Yin, L.; Zhu, J.; Li, Y.; Zeng, C.; Zhu, Q.; Qi, H.; Liu, M.; Li, W.; Cao, Z.; Yang, W.; et al. A Virtual Geographic Environment for Debris Flow Risk Analysis in Residential Areas. ISPRS Int. J. Geo-Inf. 2017, 6, 377. [CrossRef]

18. Huang, L.; Gong, J.; Li, W.; Xu, T.; Shen, S.; Liang, J.; Feng, Q.; Zhang, D.; Sun, J. Social Force Model-Based Group Behavior Simulation in Virtual Geographic Environments. ISPRS Int. J. Geo-Inf. 2018, 7, 79. [CrossRef]

19. Shen, S.; Gong, J.; Liang, J.; Li, W.; Zhang, D.; Huang, L.; Zhang, G. A Heterogeneous Distributed Virtual Geographic Environment-Potential Application in Spatiotemporal Behavior Experiments. ISPRS Int. J. Geo-Inf. 2018, 7, 54. [CrossRef]

20. Zhang, F.; Hu, M.; Che, W.; Lin, H.; Fang, C. Framework for Virtual Cognitive Experiment in Virtual Geographic Environments. ISPRS Int. J. Geo-Inf. 2018, 7, 36. [CrossRef] 